
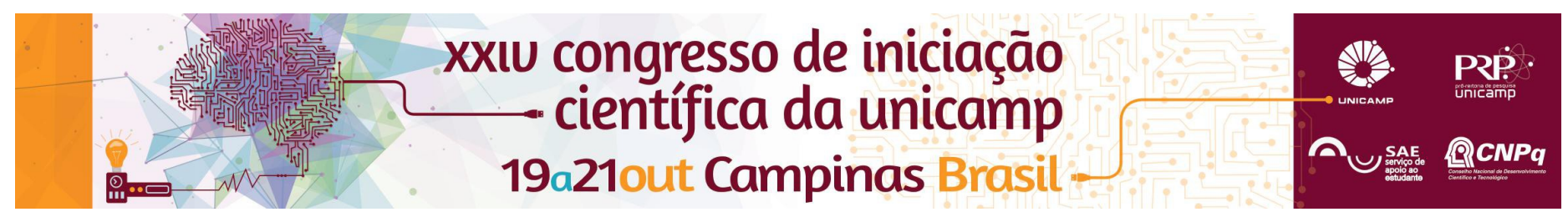

\title{
Physical Characteristics of TiO Thin Films Obtained by DC Reactive Sputtering
}

\author{
Victor C. Lima*, loshiaki Doi, Rodrigo R. Cesar, José A. Diniz \\ Abstract \\ This work presents the results of the physical characterization of $\mathrm{TiO}_{\mathrm{x}}$ thin films obtained under different deposition \\ conditions such as $\mathrm{O}_{2} / \mathrm{Ar}$ ratio and deposition plasma power using dc reactive sputtering process in order to determine \\ effects of such contiditions in the characteristics of the films.
}

\section{Key words:}

Thin films, Titanuim oxide, DC Reactive Sputtering

\section{Introduction}

In this work, two sets of the films were prepared, one set varying the sputtering discharge power ranging from 600 $\mathrm{W}$ to $1500 \mathrm{~W}$, at constant gas flow ratio of $\mathrm{Ar}=60 \mathrm{sccm}$ and $\mathrm{O}_{2}=40 \mathrm{sccm}$, and 10 minutes deposition time. Other set of the $\mathrm{TiO}_{\mathrm{x}}$ films were prepared with constant $1000 \mathrm{~W}$ deposition power for 10 minutes and gas flow $\mathrm{O}_{2} / \mathrm{Ar}$ ratio ranging from 0.166 to 0.5 . The obtained samples of both sets were all characterized by different techniques, ellipsometry, Raman spectroscopy, Atomic Force Microscopy (AFM) and Scanning Electron Microscopy (SEM) to determine thickness and refractive index of the films, crystalline structure, roughness and surface morphology, respectively.

\section{Results and Discussion}

The ellipsometry results show that deposition rate of the samples increases linearly as the power increases, and that the refractive index slightly decreases with the power increment, remaining however between 2.44 and 2.47, therefore close to the typical value of titanium oxide, the low values of standard deviation in thickness and refractive index measurements shows the depositions were homogeneous troughout the surface. As for the crystalline structure, the results of the Raman spectroscopy showed Raman shift peaks at 150, 230, $420,600,670$ and $810 \mathrm{~cm}^{-1}$, corresponding to anatase and rutile form of $\mathrm{TiO}_{x}$ thin films, which agree to those results observed by different researchers ${ }^{[1][2]}$, although no significant changes in structures proportion were noticed for different deposition conditions because of the chosen Raman method. The obtained spectra demonstrate also that the brookite structure was not found on the studied $\mathrm{TiO}_{\mathrm{x}}$ samples. AFM images showed rms roughness ranging from $0.150 \mathrm{~nm}$ for the samples obtained at 600 $\mathrm{W}$ deposition power to $0.872 \mathrm{~nm}$ for those obtained at $1500 \mathrm{~W}$ deposition power, that may explained considering increase of temperature at the sample surface and sputtered materials from the target. The characterization of the second set of the TiOx samples, showed that deposition rates increases as more $\mathrm{Ar}$ is provided to the sputtering atmosphere, as well as the refractive index, this one exhibiting a small increment as $\mathrm{O}_{2}$ ratio is increased, with low standard deviation values, showing deposition of the films with quite homogeneous surface. AFM and Raman results showed very small variations in rms roughness of the samples and crystalline structure when gas flow ratio were varied, remaining around the values of $0.441 \mathrm{~nm}$ roughness and Raman peaks of anatase and rutile crystalline structure, similar results as those observed for the first set of the samples.

\section{Conclusions}

These exhibited properties of $\mathrm{TiO}_{x}$ obtained by $\mathrm{dc}$ reactive magnetron sputtering technique allow us to determine how some deposition settings influence final physical and chemical characteristics of $\mathrm{TiO}_{\mathrm{x}}$. Such knowledge is crucial to make it an interesting material for several applications, for instances for gas sensor and dielectric in semiconducting FETs.

\section{Acknowledgement}

This work was funded by the Institucional program of scientific initiation scholarships (PIBIC), awarded by the national council of scientific and technological development (CNPq).

\footnotetext{
${ }^{1}$ CESAR R. R. DESENVOLVIMENTO DE TRANSISTOR DE EFEITO DE CAMPO SENSÍVEL A ÍON (ISFET) PARA DETECÇÃO DE CHUMBO [Relatório] : Dissertação de mestrado / Faculdade de engenharia elétrica e de computação ; Universidade estadual de Campinas. - Campinas : [s.n.], 2014.

${ }^{2}$ CESAR R.R. [et al.] Thin titanium oxide films obtained by RTP and by Sputtering [Periódico].
} 